\title{
Eating dark and milk chocolate: a randomized crossover study of effects on appetite and energy intake
}

\author{
LB Sørensen and A Astrup
} Department of Human Nutrition, Centre for Advanced Food Studies, Faculty of Life Sciences, University of Copenhagen,
Frederiksberg, Denmark

Objective: To compare the effect of dark and milk chocolate on appetite sensations and energy intake at an ad libitum test meal in healthy, normal-weight men.

Subjects/methods: A total of 16 young, healthy, normal-weight men participated in a randomized, crossover study. Test meals were $100 \mathrm{~g}$ of either milk $(2285 \mathrm{~kJ})$ or dark chocolate $(2502 \mathrm{~kJ})$. Visual-analogue scales were used to record appetite sensations before and after the test meal was consumed and subsequently every $30 \mathrm{~min}$ for $5 \mathrm{~h}$. An ad libitum meal was served $2 \mathrm{~h}$ after the test meal had been consumed.

Results: The participants felt more satiated, less hungry, and had lower ratings of prospective food consumption after consumption of the dark chocolate than after the milk chocolate. Ratings of the desire to eat something sweet, fatty or savoury were all lower after consumption of the dark chocolate. Energy intake at the ad libitum meal was $17 \%$ lower after consumption of the dark chocolate than after the milk chocolate $(P=0.002)$. If the energy provided by the chocolate is included in the calculation, the energy intake after consumption of the dark chocolate was still $8 \%$ lower than after the milk chocolate $(P=0.01)$. The dark chocolate load resulted in an overall energy difference of $-584 \mathrm{~kJ}$ (95\% confidence interval $(-1027 ;-141))$ during the test period.

Conclusion: In the present study, dark chocolate promotes satiety, lowers the desire to eat something sweet, and suppresses energy intake compared with milk chocolate.

Nutrition and Diabetes (2011) 1, e21; doi:10.1038/nutd.2011.17; published online 5 December 2011

Keywords: appetite regulation; hunger; satiety; energy intake; cocoa; chocolate

\section{Introduction}

Until a few years ago, chocolate had been regarded as an unhealthy sweet. However, recently several studies have indicated that chocolate consumption, and in particular consumption of dark chocolate, is associated with lower blood pressure, lower risk of cardiovascular disease and type 2 diabetes and lower mortality rate. ${ }^{1-8}$ It is still generally accepted that chocolate is fattening. However, there are differences between milk and dark chocolate in both ingredients and sensory properties and these differences might influence eating behaviour. For example, dark choco-

Correspondence: LB Sørensen, Department of Human Nutrition, Centre for Advanced Food Studies, Faculty of Life Sciences, University of Copenhagen, Rolighedsvej 30, DK-1958 Frederiksberg C, Denmark.

E-mail: lbs@life.ku.dk

Received 8 March 2011; revised 22 September 2011; accepted 24 October 2011 late has a more intense cocoa flavour than milk chocolate and this stronger sensory signal may lead to a stronger sensory satiety response. ${ }^{9}$ In the light of the differences between milk and dark chocolate, we propose the hypothesis that dark chocolate is more satiating than milk chocolate. This hypothesis has not been scientifically investigated previously. The objective of the present study was to compare the effect of dark chocolate and milk chocolate on appetite sensations and energy intake at an ad libitum test meal in healthy, normal-weight men.

\section{Subjects and methods}

Study design

The participants were tested on two different occasions in a randomized crossover design. On two different test days, a test meal consisting of $100 \mathrm{~g}$ of either milk or dark chocolate was served and $135 \mathrm{~min}$ later an ad libitum lunch was served. 


\section{Subjects}

A total of 23 young, healthy, normal-weight men, nonsmokers, with no history of obesity or diabetes were included. An additional inclusion criterion was that the participants should be equally fond of both milk and dark chocolate. Each participant signed an informed consent document before the start of the study. Ethical approval was not required due to the non-invasive nature of the study, but the study was registered at the Danish Data Protection Agency. The participants received three bottles of wine as an honorarium on completion of the second test day.

\section{Test meals}

The test chocolate was $100 \mathrm{~g}$ of either milk chocolate (Mælkechokolade, Marabou, Kraft Foods, Glostrup, Denmark) or dark chocolate (Guanaja, Valrhona, France) (Table 1). The chocolate was served together with $250 \mathrm{ml}$ water.

The ad libitum test meal consisted of pizza with ham and cheese. The distribution of energy was 26 energy percent (E\%) fat, $18 \mathrm{E} \%$ protein and $56 \mathrm{E} \%$ carbohydrates. The pizzas were cut in different sizes to make it difficult for the participants to compare the number of slices of pizza they ate on the two test days. The participants were asked to eat all of each pizza slice and not to leave the crust or just eat the topping. The participants were asked to drink $400 \mathrm{ml}$ water together with the ad libitum meal.

\section{Experimental protocol}

On test days, the participants arrived at the department in the morning after having fasted for at least $12 \mathrm{~h}$. Participants were weighed and recorded their baseline appetite sensations before eating $100 \mathrm{~g}$ of either milk chocolate or dark chocolate, which was consumed in the course of $15 \mathrm{~min}$. Appetite ratings were recorded on $100-\mathrm{mm}$ visual analogue scales (VAS) with words anchored at each end, describing the extremes of a unipolar question (for example for hunger: 'I am not hungry at all'/'I have never been more hungry'). VAS was used to assess hunger, satiety, fullness, prospective food consumption, desires for special foods, well-being, 'how well the chocolate was liked' ('not at all'/'very much'), and the palatability of the ad libitum test meal ('bad'/'good') (taste, smell, visual appeal, aftertaste ('none'/'much') and overall palatability). ${ }^{10}$ The participants were asked how well they liked the chocolate at time 15 min (immediately after

Table 1 Composition of $100 \mathrm{~g}$ of dark or milk chocolate

\begin{tabular}{lcc} 
& Dark chocolate & Milk chocolate \\
\hline Energy (kJ) & 2502 & 2285 \\
Protein (g) & 8.9 & 6.0 \\
Fat (g) & 42.3 & 32.0 \\
Carbohydrate (g) & 45.7 & 58.5 \\
Cocoa (\%) & 70 & 30 \\
Sugar (g) & 30.3 & 44.0 \\
\hline
\end{tabular}

consuming the chocolate) and the other appetite sensations were recorded every $30 \mathrm{~min}$ for $5 \mathrm{~h}$. An ad libitum meal was served $2 \mathrm{~h}$ after the chocolate was consumed (Figure 1 ). The participants were instructed to eat until comfortably satisfied. Palatability ratings were assessed immediately after consumption of the ad libitum meal. Energy intake was measured by weighing the amount of food consumed and converting this into energy $(\mathrm{kJ})$. The experimental room used in the study was a dining room that can normally accommodate 30 people. The number of participants on any one test day varied between one and four. Participants were allowed to sit in the experimental room and read or use their laptops throughout the test day. Physical activity was limited to visits to the restroom. The participants were allowed to talk to each other as long as the conversation did not involve food, appetite and related issues. Participants were placed so that they could not see how much the other participants consumed during consumption of the ad libitum meal. Music was played during consumption of the ad libitum test meal to draw the participants' attention away from each other and minimise the feeling of awkwardness while eating.

\section{Statistical analyses}

Baseline values were compared using a paired $t$-test. The effect of chocolate type on VAS scores was tested using a repeated measures analysis of covariance with the MIXED procedure in the Statistical Analysis System software package, version 9.1 (SAS Institute, Cary, NC, USA). For the period 15-135 min (before the ad libitum meal), baseline values were included as covariates. When adjusting for 'how well the chocolate was liked' these VAS scores were included as covariates, as well. For the period 195-315 min (after the ad libitum meal), the VAS scores at time $165 \mathrm{~min}$, the energy intake at the ad libitum meal and the overall palatability of the ad libitum meal were all included as covariates. As VAS scores are confined to the interval $(0,100)$, the scores were transformed (if $X_{i}$ denote the scores, then $Y_{i}=\arcsin$ $\sqrt{X_{i} / 100}$ ) (Figure 2). As there was a significant difference in the ratings of the desire to eat something sweet at time $165 \mathrm{~min}$, this parameter was tested by including the entire test period (15-315 min) with baseline values included as covariates (Figure 4).

The effect of type of chocolate on ad libitum energy intake and total energy intake was tested using a paired $t$-test (Figure 3). When adjusting for 'how well the chocolate was liked', an analysis of covariance was used and the VAS scores addressing this were included as covariates.

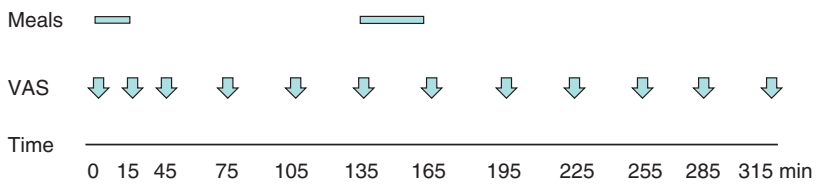

Figure 1 Protocol of the test day. 

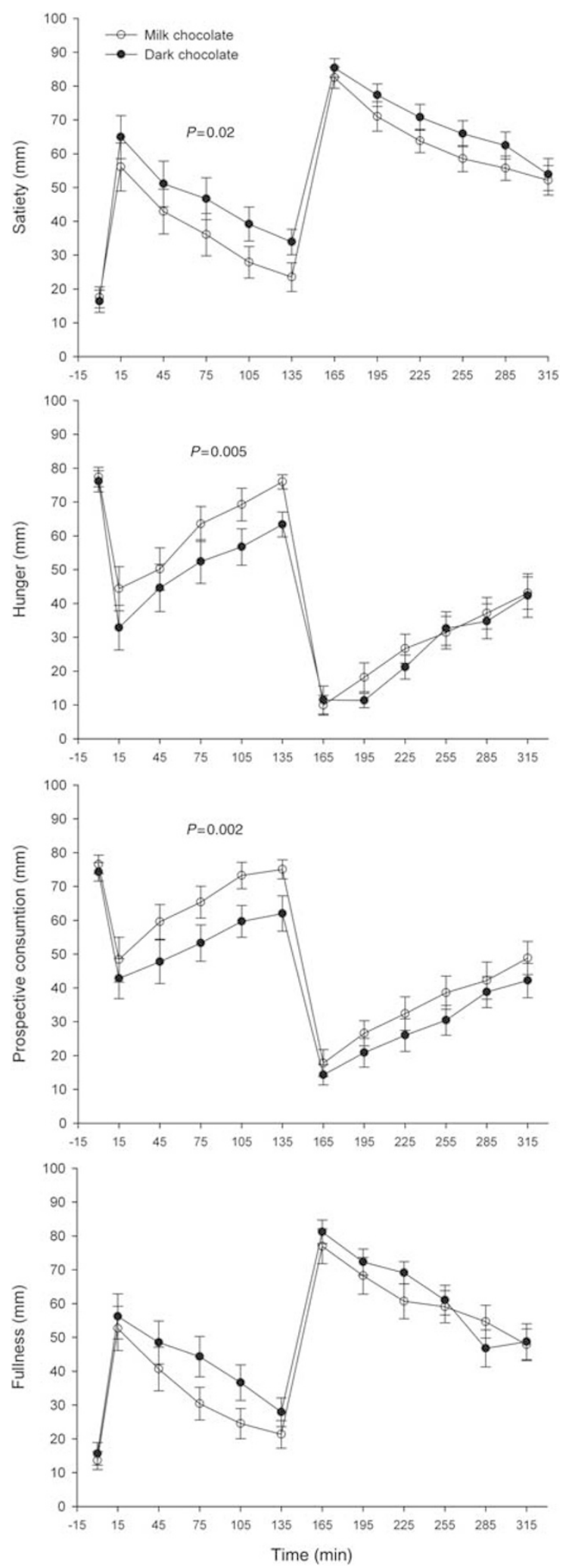

\section{Results}

Of the 23 participants, 17 completed the study. Of the 17 completers, 1 was excluded because he had consumed a large amount of alcohol on the evening before the second test day. Results from 16 participants were thus included in the final analysis. The 16 participants were $26.8 \pm 5.6$ (mean \pm s.d.) years of age and weighed $77.9 \pm 8.2 \mathrm{~kg}$ with a body mass index of $24.0 \pm 1.6 \mathrm{~kg} \mathrm{~m}^{-2}$.

There was no difference in how well the participants liked the two types of chocolate ( $P=$ not significant). The participants felt significantly more satiated $(P=0.02)$, less hungry $(P=0.005)$ and had lower ratings of prospective food consumption $(P=0.002)$ after consumption of the dark chocolate than after the milk chocolate (Figure 2). The significant differences persisted after adjusting for 'how well the chocolate was liked'. There were no significant differences between the test days with respect to sensations of fullness ( $P=$ not significant) (Figure 2 ). Ratings of the desire to eat something fatty and savoury were all significantly lower after consumption of the dark chocolate than after the milk chocolate $(P=0.0003$ and $P=0.02$, respectively).

Energy intake at the ad libitum meal was $17 \%$ lower after consumption of the dark chocolate compared with the milk chocolate $(P=0.002)$ (Figure 3$)$. Adjusting for 'how well the chocolate was liked' did not change the result. If the energy provided by the chocolate is included in the calculation, the energy intake after consumption of the dark chocolate was still $8 \%$ lower than after the milk chocolate $(P=0.01)$. Thus, the dark chocolate load resulted in an overall energy difference of $-584 \mathrm{~kJ}$ (95\% confidence

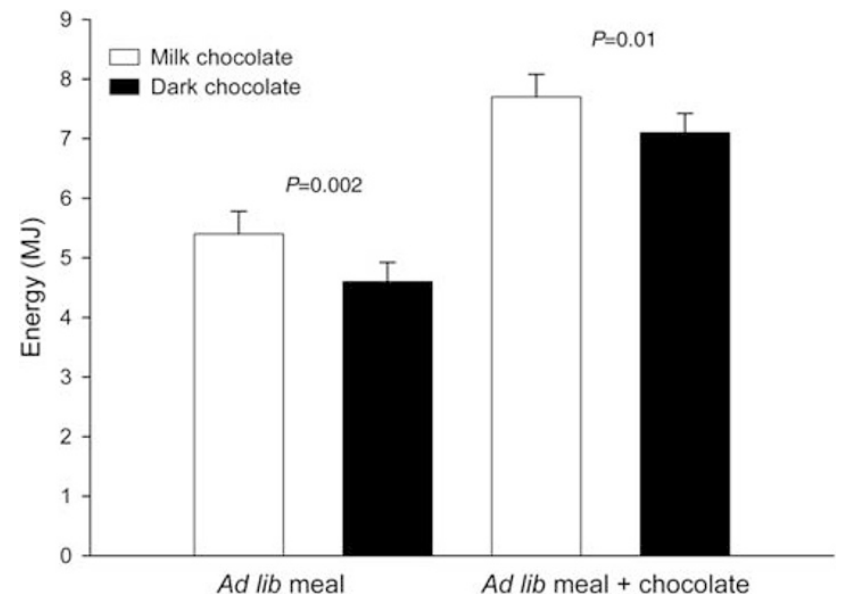

Figure 3 Mean energy intake at the ad libitum meal ( \pm s.e.m.) and total energy intake, $n=16$. The effect of meal type on ad libitum energy intake and total energy intake was tested using a paired $t$-test.

Figure 2 Mean satiety, hunger, prospective consumption and fullness VAS scores ( \pm s.e.m.) during the two test days, $n=16$. The chocolate was served at $0 \mathrm{~min}$ and the ad libitum meal at $135 \mathrm{~min}$. The $P$-values were obtained from repeated-measures analysis of covariance testing differences between postprandial appetite scores (15-135 min) — baseline values were included as covariates. 


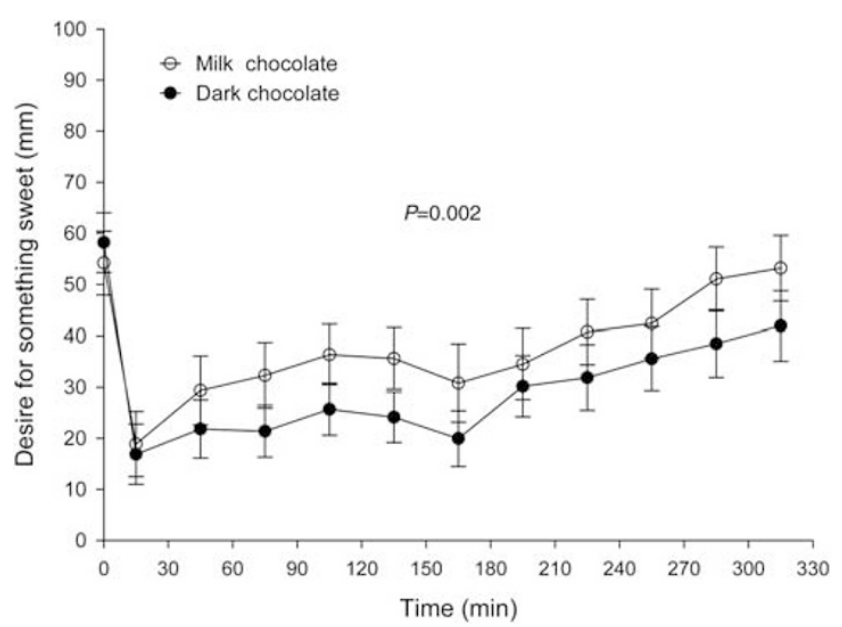

Figure 4 Mean 'desire for something sweet' VAS scores ( \pm s.e.m.) during the two test days, $n=16$. The chocolate was served at $0 \mathrm{~min}$ and the ad libitum meal at $135 \mathrm{~min}$. The $P$-value was obtained from repeated-measures analysis of covariance including the whole period $(15-315 \mathrm{~min})$ with baseline values included as covariates.

interval $(-1027 ;-141))$ during the whole test period (Figure 3 ). The palatability of the pizza was rated similarly on both the dark and milk chocolate test days.

After consumption of the ad libitum meal, there were no significant differences between the test days with respect to sensations of hunger, satiety, prospective food consumption and fullness. Nor were there any differences in subjective desires for salty, fatty or savoury foods.

The ratings of the desire to eat something sweet were significantly lower throughout the entire test day after consumption of the dark chocolate compared with the milk chocolate $(P=0.002)$ (Figure 4$)$.

There was no difference in thirst and well-being during the two test days.

\section{Discussion}

The results of the present study support the hypotheses that dark chocolate is more satiating than milk chocolate and that dark chocolate satisfies 'a sweet tooth' for a longer time than milk chocolate. As far as we know, this is the first study to compare the satiating properties of dark vs milk chocolate.

The amount of chocolate was $100 \mathrm{~g}$ of chocolate, which probably only a few people eat first thing in the morning. However, the present study was the first attempt to test whether there is a difference in the satiating effect of milk and dark chocolate. We therefore chose an amount of chocolate that was likely to be sufficient to produce a measurable difference, if any difference did in fact occur. To avoid interference from prior meals, we did the intervention in the morning, when the participants were in a fasting state. This is a standard procedure in most meal tests. Because of the crossover design, the time of chocolate consumption is not considered to have an impact on the results.

We chose to compare a good quality dark chocolate with a popular milk chocolate that would be a common choice for a Dane with a sweet tooth. The same amount of chocolate was administered regardless of the fact that the dark chocolate contained more energy than the milk chocolate. The original idea was to create a natural situation comparing the same amount of two different types of chocolate, just as would occur in the 'real' world. Unfortunately, this set-up makes the interpretation of the results more difficult because of the different energy contents of the chocolates. It could be argued that the difference in satiety may be attributable to this difference in energy intake. To our knowledge, the only way to compensate for this discrepancy in energy content would be by assuming that there is a linear relationship between preload calorie intake and subsequent food intake. There is no evidence to support this assumption, but then again there is no evidence to disprove it. When adjusted for the extra energy from the chocolate, ad libitum energy intake was still $8 \%$ lower after consumption of the dark chocolate, suggesting that the difference in satiety is not only attributable to the difference in energy content. However, it would be highly relevant to test the two types of chocolate in equal energy portions to confirm the findings from the present study.

It could be speculated that the differences in appetite on the two test days in the present study may just reflect a difference in well-being, but there were no differences in well-being between the two groups.

One of the inclusion criteria was that the participants should be equally fond of both milk and dark chocolate, but this was not tested during recruitment; the participants were simply asked whether they liked both types of chocolate. Because of the possibility that the participants could have different preferences for the two types of chocolate, we adjusted for how well the chocolate was liked. This had no significant influence on the results, which indicates that the differences between the two test days reflect a true difference in the effect of the chocolate on appetite.

It was not possible to blind the study, as the participants could easily see which type of chocolate they consumed. However, conversations during the screening process made it clear that the participants were mainly young men with no interest in nutrition, who were merely interested in having free chocolate, a free meal and some free wine (honorarium).

Why is dark chocolate more satiating than milk chocolate? The chocolates used in the present study differed most markedly in cocoa content, the amount and type of fat and sugar content. First of all, 70\% cocoa content in the dark chocolate compared with $30 \%$ in the milk chocolate results in a more intense flavour in the dark chocolate. In a recent study, the impact of the intensity of different foods on different parameters was investigated, and here it was shown that consumption of dark chocolate leads to a decreased desire to eat compared with other less 
intense-tasting foods. ${ }^{9}$ Secondly, the amount of fat was $24 \%$ greater in the dark chocolate than in the milk chocolate, and the fat in the dark chocolate was exclusively cocoa butter, whereas the milk chocolate contained both cocoa butter and butter fat. Studies have shown that cocoa butter (chocolate) has a neutral effect on blood lipids, ${ }^{11}$ and it has been suggested that this is because of the high content of stearic acid (32-36\%), which should either delay the transit time or lower the digestibility of the cocoa butter. ${ }^{11}$ However, though animal studies have shown that cocoa butter has a low digestibility, it is well absorbed in humans, both with high and moderate intakes. ${ }^{12}$ There have been no studies measuring the gastro-intestinal (GI)-transit time of cocoa butter. If the GI-transit time of the dark chocolate is longer because of the higher content of cocoa butter, then this will lead to a delayed absorption of fat in the GI tract. A delayed absorption of fat leaves more undigested fatty acids in the GI tract, which could lead to increased release of appetite-regulating GI hormones, such as cholecystokinin, glucagon-like peptide-1 and peptide YY. ${ }^{13-15}$

The protein content was $2.9 \mathrm{~g}$ (33\%) higher in the dark chocolate than in the milk chocolate corresponding to 8.9 E\% and 6.0 E\%, respectively. Several single-meal studies with high-protein diets (25 $\mathrm{E} \%$ or more) have shown increased satiety from protein. ${ }^{16}$ As far as we know, only one study has been done with low doses of protein, and in that study low-dose protein-enriched beverages (1-4 E\%) suppressed subjective feelings of hunger and fullness but had no significant effect on energy intake 120 min after consumption of the protein preload. ${ }^{17}$ This suggests that the difference in protein content in the present study does not explain the difference in the effect on energy intake.

It could be speculated that the differential effects of the two types of chocolate may be explained both by the difference in the sensory properties (for example, the flavour intensity) and a difference in GI-transit time, as well. We expected an immediate effect on the ratings of appetite due to the differences in the sensory properties of the two chocolates and this is reflected in the VAS slopes. The continuing difference in appetite could be due to an increasing effect originating from different GI-transit times that gradually overlap the decline in the effect of the sensory properties.

When a food is eaten, this food (and other related foods) drops in ratings of pleasantness relative to foods that have not been eaten. This phenomenon is referred to as sensoryspecific satiety. ${ }^{18}$ According to this phenomenon, it could be expected that the desire to eat something sweet would be lower after consuming the milk chocolate compared with the dark chocolate, as the milk chocolate was sweeter. However, this was not the case and the decrease in the desire to eat something sweet immediately after eating the chocolate was the same for both types, whereas ratings were higher for the remainder of the test period on the milk-chocolate test day compared with the dark-chocolate test day.

As chocolate is an energy rich food, it would be relevant to compare the effect of smaller amounts of dark and milk chocolate on appetite and energy intake and on body weight. A long-term study with fixed amounts of chocolate as a dietary supplement and using ad libitum test meals would be one way to investigate this. In order to learn more about the mechanisms behind the differences in the effect of the chocolates on appetite, the present study could be repeated (with equal energy portions) with the inclusion of assessments of the subjects' perception of the sensory properties of the chocolates, measurements of gastric emptying and concentrations of cholecystokinin, glucagon-like peptide-1 and peptide YY. A study examining the effects of chocolate ad libitum on satiety and satiation would also be relevant.

In conclusion, the present results suggest that dark chocolate promotes satiety, lowers the desire to eat something sweet and suppresses energy intake compared with milk chocolate, although further research is needed to validate these results.

\section{Conflict of interest}

Professor A Astrup received research support from more than 100 food companies for other studies. Professor Astrup reports serving as an executive board member of Obesity International Trading (United Kingdom), Beer Knowledge Institute (the Netherlands), Global Dairy Platform (United States) and Nordic Food Lab (Denmark); serving on the European Almond Advisory Board and on the boards of 7TM Pharma, NeuroSearch, Basic Research, Merck, Johnson \& Johnson Pharmaceutical Research \& Development, Jenny Craig and Kraft; acting as a consultant or advisory board member for 7TM Pharma, NeuroSearch, Basic Research, Merck, Johnson \& Johnson Pharmaceutical Research \& Development, Pfizer, Vivus, Jenny Craig, Almond Board of California and Kraft; and receiving lecture fees from the Almond Board of California, Arla, Campina and Astellas Pharma. LB Sorensen declares no conflict of interest.

\section{Acknowledgements}

We thank Yvonne Fatum, Charlotte Kostecki and Christina Cuthbertson for the technical support, and Maiken Juul Hansen, Marianne From, Eva Nydal Jensen and Fatma Al-Abaiji for their help with data collection. We gratefully acknowledge the participation of all the persons involved in the study. The study was funded by an internal grant from the Department of Human Nutrition, Faculty of Life Sciences, University of Copenhagen, Denmark.

\section{References}

1 Grassi D, Desideri G, Ferri C. Blood pressure and cardiovascular risk: what about cocoa and chocolate? Arch Biochem Biophys 2010; 501: 112-115. 
2 Faridi Z, Njike VY, Dutta S, Ali A, Katz DL. Acute dark chocolate and cocoa ingestion and endothelial function: a randomized controlled crossover trial. Am J Clin Nutr 2008; 88: 58-63.

3 Allen RR, Carson L, Kwik-Uribe C, Evans EM, Erdman Jr JW. Daily consumption of a dark chocolate containing flavanols and added sterol esters affects cardiovascular risk factors in a normotensive population with elevated cholesterol. I Nutr 2008; 138: 725-731.

4 Taubert D, Roesen R, Lehmann C, Jung N, Schomig E. Effects of low habitual cocoa intake on blood pressure and bioactive nitric oxide: a randomized controlled trial. JAMA 2007; 298: 49-60.

5 Grassi D, Lippi C, Necozione S, Desideri G, Ferri C. Short-term administration of dark chocolate is followed by a significant increase in insulin sensitivity and a decrease in blood pressure in healthy persons. Am J Clin Nutr 2005; 81: 611-614.

6 Mursu J, Voutilainen S, Nurmi T, Rissanen TH, Virtanen JK, Kaikkonen J et al. Dark chocolate consumption increases HDL cholesterol concentration and chocolate fatty acids may inhibit lipid peroxidation in healthy humans. Free Rad Bio Med 2004; 37: 1351-1359.

7 Wan Y, Vinson JA, Etherton TD, Proch J, Lazarus SA, Kris-Etherton PM. Effects of cocoa powder and dark chocolate on LDL oxidative susceptibility and prostaglandin concentrations in humans. Am J Clin Nutr 2001; 74: 596-602.

8 Lee IM, Paffenbarger RSJ. Life is sweet: candy consumption and longevity. BMJ 1998; 317: 1683-1684.

9 Weijzen PLG, Zandstra EH, Alfieri C, de Graaf C. Effects of complexity and intensity on sensory specific satiety and food acceptance after repeated consumption. Food Qual Pref 2008; 19: 349-359.

10 Raben A, Tagliabue A, Astrup A. The reproducibility of subjective appetite scores. Br J Nutr 1995; 73: 517-530.
11 Steinberg FM, Bearden MM, Keen CL. Cocoa and chocolate flavonoids: implications for cardiovascular health. J Am Diet Assoc 2003; 103: 215-223.

12 Shahkhalili Y, Duruz E, Acheson K. Digestibility of cocoa butter from chocolate in humans: a comparison with corn-oil. Eur J Clin Nutr 2000; 54: 120-125.

13 Holst JJ. The physiology of glucagon-like peptide 1. Physiol Rev 2007; 87: 1409-1439.

14 le Roux CW, Bloom SR. Peptide YY, appetite and food intake. Proc Nutr Soc 2005; 64: 213-216.

15 Liddle RA, Goldfine ID, Rosen MS, Taplitz RA, Williams JA. Cholecystokinin bioactivity in human plasma. Molecular forms, responses to feeding, and relationship to gallbladder contraction. I Clin Invest 1985; 75: 1144-1152.

16 Westerterp-Plantenga MS, Nieuwenhuizen A, Tomé D, Soenen S, Westerterp KR. Dietary protein, weight loss, and weight maintenance. Annu Rev Nutr 2009; 29: 21-41.

17 Poppitt SD, Proctor J, McGill AT, Wiessing KR, Falk S, Xin L et al. Low-dose whey protein-enriched water beverages alter satiety in a study of overweight women. Appetite 2011; 56: 456-464.

18 Sorensen LB, Moller P, Flint A, Martens M, Raben A. Effect of sensory perception of foods on appetite and food intake: a review of studies on humans. Int J Obes 2003; 27: 1152-1166.

This work is licensed under the Creative Commons Attribution-NonCommercial-No Derivative Works 3.0 Unported License. To view a copy of this license, visit http://creativecommons.org/ licenses/by-nc-nd/3.0/ 